\title{
Effects of leucine supplemented diet on intestinal absorption in tumor bearing pregnant rats Gislaine Ventrucci ${ }^{1}$, Maria Alice Roston de Mello ${ }^{2}$ and Maria Cristina Cintra Gomes-Marcondes*1
}

Address: ${ }^{1}$ Dept Physiology \& Biophysics, Biology Institute, UNICAMP, Brazil. 13083-970 and 2Physiology \& Biophysics, Bioscience Institute, UNESP, Brazil. 13506-900

E-mail: Gislaine Ventrucci - ventrucc@unicamp.br; Maria de Mello - mellomar@rc.unesp.br; Maria Gomes-Marcondes* - cintgoma@unicamp.br ${ }^{*}$ Corresponding author

Published: 15 April 2002

BMC Cancer 2002, 2:7

This article is available from: http://www.biomedcentral.com/I47/-2407/2/7

(C) 2002 Ventrucci et al; licensee BioMed Central Ltd. Verbatim copying and redistribution of this article are permitted in any medium for any purpose, provided this notice is preserved along with the article's original URL.

Received: 5 December 200I

Accepted: 15 April 2002

\begin{abstract}
Background: It is known that amino acid oxidation is increased in tumor-bearing rat muscles and that leucine is an important ketogenic amino acid that provides energy to the skeletal muscle.

Methods: To evaluate the effects of a leucine supplemented diet on the intestinal absorption alterations produced by Walker 256 , growing pregnant rats were distributed into six groups. Three pregnant groups received a normal protein diet (18\% protein): pregnant $(\mathrm{N})$, tumor-bearing $(\mathrm{WN})$, pair-fed rats $(\mathrm{Np})$. Three other pregnant groups were fed a diet supplemented with $3 \%$ leucine ( $15 \%$ protein plus $3 \%$ leucine): leucine (L), tumor-bearing $(W L)$ and pair-fed with leucine $(L P)$. Non pregnant rats (C), which received a normal protein diet, were used as a control group. After 20 days, the animals were submitted to intestinal perfusion to measure leucine, methionine and glucose absorption.
\end{abstract}

Results: Tumor-bearing pregnant rats showed impairment in food intake, body weight gain and muscle protein content, which were less accentuated in $W L$ than in $W N$ rats. These metabolic changes led to reduction in both fetal and tumor development. Leucine absorption slightly increased in WN group. In spite of having a significant decrease in leucine and methionine absorption compared to $\mathrm{L}$, the $\mathrm{WL}$ group has shown a higher absorption rate of methionine than $W N$ group, probably due to the ingestion of the leucine supplemented diet inducing this amino acid uptake. Glucose absorption was reduced in both tumor-bearing groups.

Conclusions: Leucine supplementation during pregnancy in tumor-bearing rats promoted high leucine absorption, increasing the availability of the amino acid for neoplasic cells and, mainly, for fetus and host utilization. This may have contributed to the better preservation of body weight gain, food intake and muscle protein observed in the supplemented rats in relation to the nonsupplemented ones.

\section{Background}

Cachexia is a debilitating state and still poorly understood syndrome of progressive body weight loss present in many types of cancer. It is characterized by host involun- 
tary weight loss, anorexia and metabolic alterations [1]. The anorexia-cachexia syndrome is a complex metabolic and behavioral alteration correlated with poor outcome and compromised quality of life, leading to death $[2,3]$. Loss of protein is a major factor in the short survival time of patients with cachexia and may also contribute to the immunologic abnormalities [2]. Despite the controversy about the underlying molecular mechanism of cancer cachexia, the growing tumor has a considerable demand for essential amino acids and glucose. The tumor daily nutrient needs can increase considerately, especially for leucine [4]. As a result of the demand for leucine there is an amino acid flux from muscle to the tumor associated with muscular wastage in the host [4].

Muscle wasting may be due to increased protein catabolism, decreased protein synthesis, or a combination of the two [2]. Smith and Tisdale [5] demonstrated that serum from cachectic animals was able to increase protein degradation in isolated gastrocnemius muscle, while serum from mice bearing MAC13 adenocarcinoma, which is not associated to cachexia, did not increase protein breakdown.

Branched-chain amino acids (BCAA: leucine, isoleucine and valine) are essential nutrients for both humans and animals, making up to $40 \%$ of the animal daily requirements of indispensable amino acids for humans [6], leucine alone representing $8 \%$ of body protein in human [7].

In the study of the mechanism that leads to protein waste, particular interest has been given to the metabolism of BCAA [8]. The carbon skeletons arising from transamination of BCAA provide the major source of metabolic fuel for skeletal muscle. Argiles and Lopez-Soriano [9] have shown that during cancer, the BCCA plasma levels were often increased and their turnover rates altered. It has been previously demonstrated that in vivo leucine oxidation to $\mathrm{CO}_{2}$ is enhanced in tumor-bearing animal [9-11] and associated to an increased amino acid turnover.

Experiments studying reciprocal influence between cancer and pregnancy still remain controvertial indicating that, in some cases, pregnancy has a protective mechanism against tumor [12] or that there is an increase in fetal resorption incidence and a decrease in fetal weight $[13,14]$.

In our previous studies, it has been shown that a leucine supplemented diet could prevent, in part, the high cell nitrogen wastage (expressed by non-collagen nitrogen) in pregnant tumor-bearing rats [15].

Amino acids absorption can occur by co-transport system and facilitated transport systems through cellular pathways. The intestinal amino acids transport capacity is re- lated to the animal age and depends on the microvilli and the number of carrier on the brush border [16]. The determination of nutrients or amino acids absorption in certain pathologies is an important condition to assure the best dietary program to be given in these cases. Furthermore, this is an important issue in the study of cancer, since altered intestinal absorption may alter blood chemistry and contribute to anorexia genesis. To investigate the effects of a leucine supplemented diet on leucine, methionine and glucose intestinal absorption in the presence of Walker 256 tumor growth was the main purpose of the study reported here.

\section{Methods}

\section{Animals and diets}

Young female Wistar rats (45 days old, $\mathrm{N}=60$ ) were obtained from the animal facilities of University of Campinas, São Paulo, Brazil. The females rats were placed with adults males (90-100 days old, 4 females: 1 male) in collective cages during one night (12 hours), in agreement with harem methodology [17]. The first day of pregnancy was determined following detection of sperm in vaginal smear.

All animals were kept in metabolic cages under normal conditions $\left(22+2^{\circ} \mathrm{C}, 12 / 12 \mathrm{~h}\right.$ light/dark cycle $)$ with free access to water and food during 20 days.

The semi purified control diet contained $18 \%$ protein, $63 \%$ carbohydrate, $7 \%$ fat, and 5\% fibers - AIN-93G [18]. High leucine diet contained $15 \%$ protein added $3 \%$ L-leucine and same amount carbohydrate, fat and fibers percentage as the control diet.

\section{Groups of rats studied}

The female rats were distributed into 7 groups: four groups were fed with semi-purified control diet: non-pregnant, $\mathrm{C}$; pregnant, $\mathrm{N}$; pregnant tumor-bearing rat, WN; pregnant pair-fed group, $\mathrm{Np}$, receiving the same amount of food ingested by tumor-bearing group WN. Three other pregnant groups were fed with semi-purified leucine supplemented diet: pregnant, L; pregnant tumor-bearing, WL; and pregnant pair-fed rat receiving leucine supplemented diet in the same amount ingested by WL group, Lp.

\section{Tumor implantation}

Groups WN and WL were subcutaneously implanted with Walker 256 tumor cell suspension (approx. 0,25 × $10^{6}$ in $0,5 \mathrm{~mL}$ of saline) in the right flank of the rats. These pregnant groups were injected with tumor cells immediately after the detection of the pregnancy. The groups without tumor were injected with $0,5 \mathrm{~mL} \mathrm{0,9 \% (w.v.)} \mathrm{NaCl}$ without anesthesia. 
All experiments were commenced between 8:00 and 10:00 am, and followed during 20 days after tumor implantation.

General UKCCR (1988, United Kingdom Coordinating Committee on Cancer Research) for animal welfare were followed (Ethical Committee for Animal Research CEEA and COBEA, Brazil, no. 034-2).

\section{Experimental proceedings}

Food intake and body weight were measured every two days. Tumor weight was calculated from 3 orthogonal linear measurements using the weight dimension curves [15].

After 20 days all experimental groups were submitted to continuing intestinal perfusion, as described by GomesMarcondes et al [19]. The intestinal perfusate fluid samples were taken to measure leucine, methionine and glucose content after flux perfused solution containing 138,7 $\mu \mathrm{mol} / \mathrm{L}$ glucose, or $167,5 \mu \mathrm{mol} / \mathrm{L}$ DL-methionine or 190,5 $\mathrm{mol} / \mathrm{L}$ L-leucine; polyethylene glycol (PEG, 4000 mo. Wt) was added to perfused solution as a tracer in nutrients uptake studies. The flow rate was 0,5 to $1,0 \mathrm{~mL} /$ $\min$ at $37^{\circ} \mathrm{C}, \mathrm{pH} 7,0$, during $60 \mathrm{~min}$.

The animals were killed after Nembutal hyper dose followed by cervical dislocation. Arterial blood samples were collected to determine glucose, total protein and, albumin and gastrocnemius muscle samples were weighted and determined the total protein content.

\section{Biochemical determinations}

Intestinal perfusate solution and blood glucose were determined by colorimetric method, Trinder [19]. Methionine and leucine perfused solution were measured following the spectrophotometric methods described by McCarthy \& Sulivan [20] and Rosen [21] respectively. Total protein content was analyzed using colorimetric method [22].

\section{Statistical analysis}

The Kruskal-Wallis one way analysis [23] assessed statistical differences, using the GraphPad Prism, v 3.00 for Windows 98. The comparisons among groups were considered statistically significant when the $P$ value was below 5\% level.

\section{Results \\ Effect of Walker 256 tumor-bearing on body weight, food intake and fetal weight}

In this study, changes in body and tumor weight were longitudinally monitored. These data are show in Table 1 . In both pregnant groups, the tumor growth promoted a sharp decrease in food intake; there was a $58 \%$ decrease in $\mathrm{WN}$ compared to $\mathrm{N}$ groups, and this decrease was less intense in WL group (50\%). Since sharp decrease in food intake has been demonstrated in several studies with tumorbearing organisms $[2,24]$, the same restriction in food intake was imposed to pair-fed groups in the present study.

The body weight gain was significantly reduced in WN and WL groups compared to their respective control groups (50\% in WN and $42 \%$ in WL group). In pair-fed groups the body weight gain was less impaired compared to tumor-bearing, around $42 \%$ in $\mathrm{Np}$ and $38 \%$ in Lp.

Table I: Body weight gain (total body weight on $20^{\text {th }}$ day), food intake, tumor weight/carcass weight, fetal weight of the groups studied.

Body weight gain (\%)

Food intake (\%)

Tumor weight/carcass weight (\%)

Fetal weight $(\mathrm{g})$

$\begin{array}{cc}C & 30,21 \pm 0,27 \\ N & 45,02 \pm 1,32 \mathrm{a} \\ W N & 22,83 \pm 0,53 \mathrm{~b} \\ \text { Np } & 26,01 \pm 1,07 \mathrm{~b} \\ \mathrm{~L} & 43,19 \pm 1,30 \mathrm{a} \\ \mathrm{WL} & 24,87 \pm 0,61 \mathrm{~b} \\ \text { LP } & 26,78 \pm 0,44 \mathrm{~b}\end{array}$

$98,77 \pm 4,55$
$95,75 \pm 4,85$
$40,01 \pm 3,56 \mathrm{ab}$
$82,40 \pm 8,64$
$41,29 \pm 3,63 \mathrm{ab}$

$98,77 \pm 4,55$

$95,75 \pm 4,85$

$82,40 \pm 8,64$
$41,29 \pm 3,63$ ab

$\begin{array}{cc}7,81 \pm 0,27 & 3,73 \pm 0,13 \\ & 1,61 \pm 0,22 b \\ & 2,98 \pm 0,34 \\ 7,46 \pm 0,33 & 3,45 \pm 0,16 \\ & 1,15 \pm 0,16 b \\ & 2,77 \pm 0,44\end{array}$

Body weight gain was determined from the rate final body weight gain in relation to initial body weight gain (\%). Food intake was expressed as a percentage of initial and final food intake (\%) Data are reported as means \pm SE from 10 animals per group. Groups: control (C); pregnant control (N); pregnant tumor-bearing (WN); pregnant control pair-fed to tumor-bearing groups (Np); pregnant control receiving a leucine supplemented diet (L), pregnant tumor-bearing receiving a leucine supplemented diet $(W L)$ and pregnant control leucine pair-fed group (Lp). a $p<0,05$ compared to control group (C); b $p<0,05 \mathrm{~N}$ vs $\mathrm{WN}$ and $\mathrm{L}$ vs $\mathrm{WL}$. 
The same tumor weight was observed in both pregnant tumor-bearing groups. The tumor/carcass weight ratio was around $7 \%$ in both groups.

Fetal weight reduction (57\% and $66 \%$, respectively) was observed in $\mathrm{WN}$ and $\mathrm{WL}$ rats compared to pregnant rats. In pair-fed groups, the fetal weight decrease was not as intense as in tumor-bearing groups (around 20\% in the both groups).

\section{Effects of Walker 256 tumor-bearing on circulating param-} eters

Blood glucose, total protein and albumin data are shown in Table 2.

Table 2: Glucose, total protein and albumin serum of the groups studied.

\begin{tabular}{cccc}
\hline & $\begin{array}{c}\text { Glucose serum } \\
(\mathrm{nmol} / \mathrm{L}-\mathrm{I})\end{array}$ & $\begin{array}{c}\text { Serum total protein } \\
(\mathrm{g} / \mathrm{dL})\end{array}$ & $\begin{array}{c}\text { Serum albumin } \\
(\mathrm{g} / \mathrm{dL})\end{array}$ \\
\hline & & & \\
$\mathrm{C}$ & $5,35 \pm 0,15$ & $7,86 \pm 0,50$ & $2,30 \pm 0,29$ \\
$\mathrm{~N}$ & $4,23 \pm 0,21 \mathrm{a}$ & $6,47 \pm 0,49$ & $2,8 \mathrm{I} \pm 0,3 \mathrm{I}$ \\
$\mathrm{WN}$ & $3,56 \pm 0,15 \mathrm{ac}$ & $5,06 \pm 0,32$ & $2,20 \pm 0,23 \mathrm{c}$ \\
$\mathrm{Np}$ & $4,17 \pm 0,2 \mathrm{I} \mathrm{a}$ & $5,82 \pm 0,23$ & $2,70 \pm 0,33$ \\
$\mathrm{~L}$ & $5,34 \pm 0,21 \mathrm{~b}$ & $5,90 \pm 0,48$ & $2,92 \pm 0,28$ \\
$\mathrm{WL}$ & $4,90 \pm 0,18 \mathrm{~b}$ & $4,72 \pm 0,24$ & $2,28 \pm 0,32 \mathrm{c}$ \\
$\mathrm{LP}$ & $5,26 \pm 0,1 \mathrm{l} \mathrm{b}$ & $5,59 \pm 0,26$ & $3,14 \pm 0,5 \mathrm{I}$ \\
& & & \\
\hline
\end{tabular}

Data are reported as means \pm SE from 10 animals per group. Groups: control (C); pregnant control (N); pregnant tumor-bearing (WN); pregnant control pair-fed to tumor-bearing groups (Np); pregnant control receiving a leucine supplemented diet $(L)$, pregnant tumorbearing receiving a leucine supplemented diet $(\mathrm{WL})$ and pregnant control leucine pair-fed group (Lp). a $p<0,05$ compared to control group (C); b p $<0,05$ comparison among $L, W L$ and Lp groups to $N, W N$ and $\mathrm{Np}$, respectively, $c p<0,05 \mathrm{~N}$ vs $\mathrm{WN}$ and $\mathrm{L}$ vs $\mathrm{WL}$.

Blood glucose decreased in pregnant groups, with and without tumor, in relation to non-pregnant group and this decrease was especially pronounced in WN groups. The leucine supplemented diet groups did not show alterations in blood glucose compared to non-pregnant group; but their values were significantly higher when compared to $\mathrm{N}, \mathrm{WN}$ and Np groups, around $26 \%$.

Despite of similar serum total protein values, serum albumin was decreased in both tumor-bearing groups compared to respective non tumor-bearing groups ( $\mathrm{N}$ and $\mathrm{L}$, Table 2).

\section{Effects of Walker 256 carcinoma on gastrocnemius muscle weight and protein}

Tumor growth caused a pronounced decrease in muscle weight and protein content in WN and WL groups (Figure
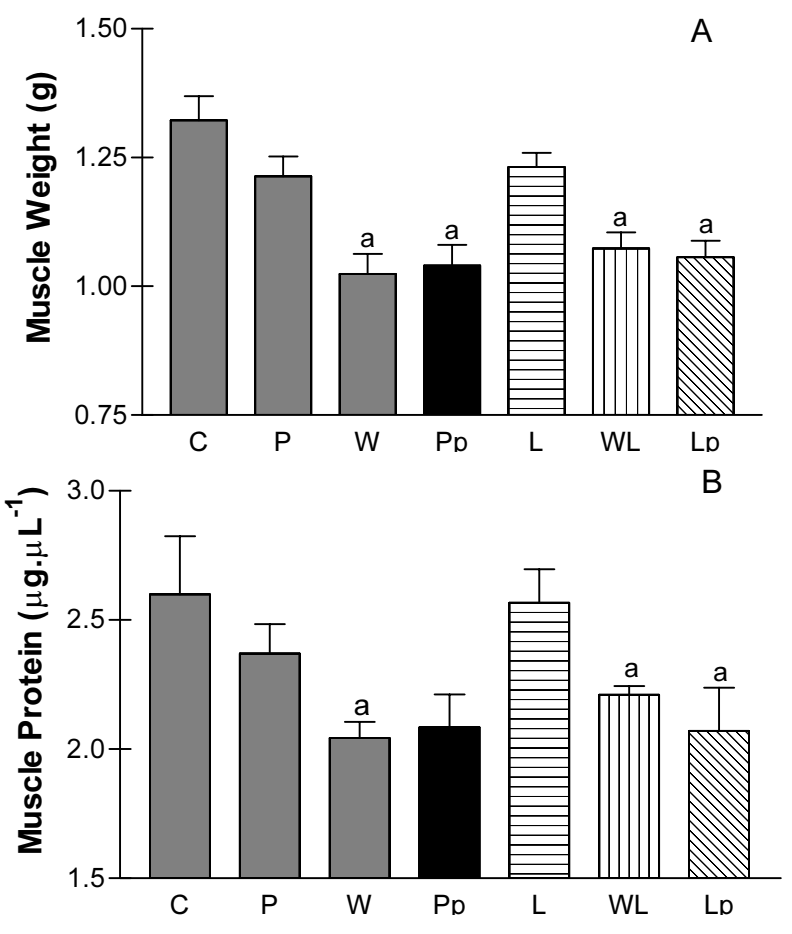

\section{Figure I}

Changes in gastrocnemius muscle weight $(A)$ and protein content (B) in virgin and pregnant groups. C, virgin control group; $\mathrm{N}$ pregnant group; $\mathrm{WN}$ pregnant tumor-bearing group; Np pregnant pair-fed group; leucine supplemented diet groups: L pregnant group; WL pregnant tumor-bearing and Lp pregnant pair-fed group. Data are means \pm SE. a $p<$ 0.05 vs control group $(C)$, differences were determined using two-way ANOVA followed by Dun's test.

1). Analyzing the leucine supplemented diet groups, although WL groups presented decrease in muscle protein content in comparison to L group, the values were slightly higher than in $\mathrm{WN}$ group.

\section{Intestinal Absorption during Walker 256 tumor growth}

Glucose, methionine and leucine absorption data are shown in Figure 2. The pregnant state caused a significant increase in glucose absorption in relation to non-pregnant state independently of the diet treatment. This increase was around two fold in both $\mathrm{N}$ and L groups (Figure 2A).

Tumor growth promoted significant decrease in glucose absorption, of $50 \%$ in WN and 30\% in WL groups. Both pair-fed groups also presented a decrease in glucose absorption (42\% in Np and non-significant 25\% decrease in Lp). 

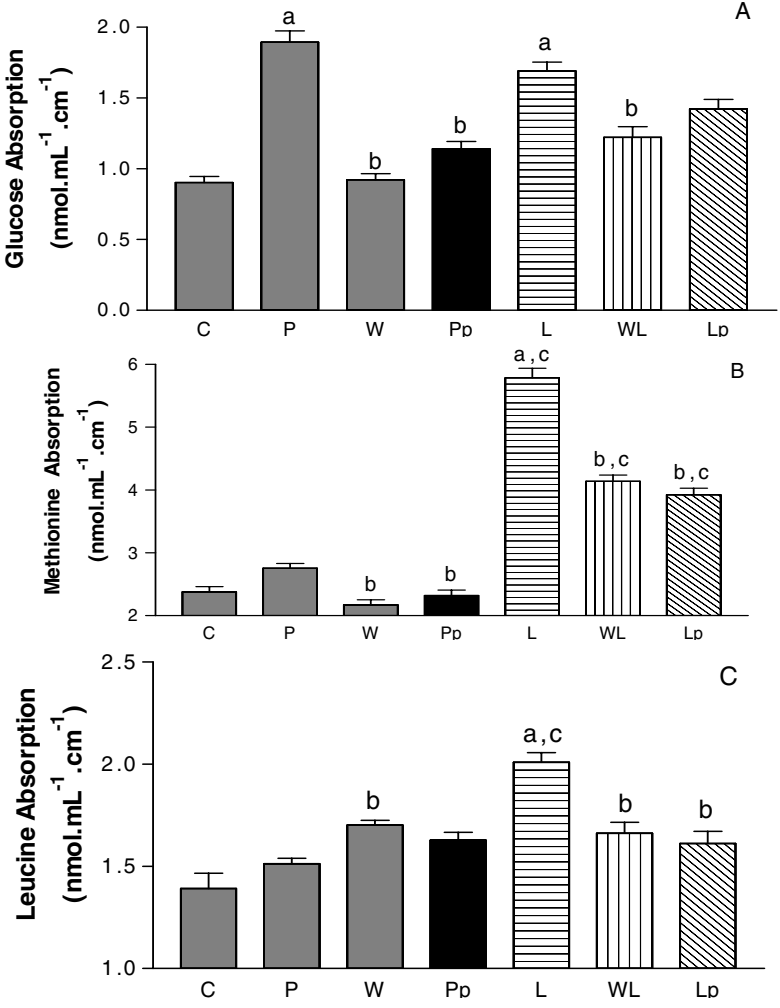

Figure 2

Changes in glucose (A), methionine (B) and leucine $(C)$ intestinal absorption rates in virgin and pregnant groups. $C$, virgin control group; $\mathrm{N}$ pregnant group; $\mathrm{WN}$ pregnant tumor-bearing group; Np pregnant pair-fed group; leucine supplemented diet groups: L pregnant group; WL pregnant tumor-bearing and Lp pregnant pair-fed group. Data are means \pm SE. a $p<$ 0.05 vs control group (C); b $p<0.05$ comparison $N$ vs $W N$, $\mathrm{Np}$, and L VS WL; c $p<0.05$ comparison normoprotein diet vs excess diet.

Methionine absorption (Figure 2B) was slightly increased in $\mathrm{N}$, but it was 5 fold higher in L group compared to nonpregnant group. Tumor-growth induced decrease in food intake reduced methionine absorption in WN (20\%) and WL group (30\%). Similar decrease in this amino acid absorption was observed in both pair-fed groups.

In contrast, leucine absorption was not increased in the $\mathrm{N}$ group. On the other hand, in pregnant groups which received the leucine supplemented diet the absorption rate was 1.5 fold higher than non-pregnant group.

Although amino acid absorption is controlled by carrier transport, which can be increased or unchanged by food deprivation, in tumor-bearing group WN the leucine absorption was higher compared to non-pregnant and preg- nant group, suggesting increased nutrient offer to provide the neoplasic cells proliferation. On the other hand, the leucine supplemented diet group implanted with Walker 256 tumor presented a decrease in leucine absorption rate, differently from the pattern showed by WN group.

\section{Discussion}

This study demonstrates that the tumor growth produces some host alterations in pregnant rats, which can be attenuated by feeding leucine supplemented diet. In the present experiments we observed reduction in some parameters in WL group, such as food intake, body weight gain, muscle protein content, which were less pronounced than in WN group (Table 1 and Figure 1).

Reduction in food intake is frequently observed in animals and patients with cancer and the mechanism involved in the genesis of this process still remains unknown. The tumor -bearing state is associated with a decrease in the host insulin: glucagon ratio. Increased glucagon levels can lead to anorexia, as well as increased hepatic gluconeogenesis and utilisation of gluconeogenic amino acids at the expense of protein synthesis, leading to a negative energy balance [25]. In a recent study, decrease on food intake was observed in Walker tumor -bearing rats associated to highly decrease in carcass weight $[13,14]$.

Anorexia is always associated with a pronounced reduction in body weight gain, in spite of the fact that many studies have demonstrated that cachexia is a much more complex process than this simple association. Here in this study a significant reduction in body weight was observed in association with decrease in food intake, but these alterations were less pronounced in pair-fed groups than in tumor bearing groups. Depletion of lean body mass in cancer cachexia is a major factor responsible for the reduced survival time of cancer patients [2]. Both reduced rates of protein synthesis and increased rates of protein degradation have been observed in biopsies of skeletal muscle from cachetic-cancer patients. While muscle-protein synthesis is depressed, syntheses of secretory proteins, such as acute-phase reactants by the liver are actually increased, so that there may be no change in total body-protein synthesis. However, in cancer patients muscle-protein synthesis only accounted for $8 \%$ of total body synthesis versus $53 \%$ for healthy control subjects.

Loss of skeletal-muscle mass in both cancer patients and an experimental model of cachexia in the mouse has been shown to correlate with the presence in the serum of bioactivity capable of inducing protein degradation in isolated skeletal muscle. Tisdale and his group [2] have found a glicoprotein, named proteolysis-inducing factor (PIF), which can promote proteolysis in skeletal muscle of ca- 
chetic tumor and in non tumor -bearing animals. Our results showed decrease in muscle weight and protein content in tumor bearing rats, especially in the WN group. These results suggest that probably the leucine supplemented diet can improve the protein synthesis process or inhibit the degradation mechanism in tumor bearing host.

Positive effects of leucine ingestion have been observed in tissues in catabolic states. McNurlan et al. [26] have investigated the effect of leucine on protein synthesis in starvation and protein depletion, and suggested that both states were characterised by loss of body nitrogen and low rates of tissue protein synthesis. Under these conditions, Li \& Jefferson [27] demonstrated that leucine stimulates protein synthesis in perfused skeletal muscle. Branched-chain amino acids (BCAA; leucine, isoleucine, and valine) have long been recognised as having a clear inhibitory action on proteolysis in skeletal muscle [27]. Leucine has been shown to stimulate incorporation of amino acids into skeletal and cardiac muscle protein [28] and further to inhibit protein degradation in liver $[29,30]$ and skeletal muscle [28]. In vivo studies in rats failed to demonstrate any effects of leucine on protein synthesis, but in humans, a mixture of amino acids was reported to stimulate protein synthesis [26].

Studies with human subjects indicate that the nitrogen balance is improved in response to BCAA administration in conditions in which a negative nitrogen balance exists (e.g., starvation, surgery, acute hepatic failure, and cancer) [35,32]. Schaur et al. [33] found that dietary administration of BCAA (leucine and isoleucine) to tumor -bearing rats caused a limited increase in survival time and decrease in tumor growth. Moreover, it has been shown that insulin effects on muscle protein synthesis in vivo are enhanced by BCAA infusion [34]. These results support the hypothesis that BCAA may give important signals in controlling muscle protein turnover.

The results presented here clearly show that leucine is able to attenuate the muscle proteolysis in tumor-bearing rats. This effect was expressed in body weight gain, food intake and muscle protein content. An elegant experiment, done by Busquets et al. [35] showed that leucine can influence gene expression for the different proteolytic system ubiquitin, inducing a significant decrease in the expression of the ubiquitin genes. Furthermore, the presence of the amino acid also caused a decrease in the C8 subunit of the proteasome. It has to be pointed out that the muscles did not show any significant change that could affect the ATPrequiring ubiquitin system in either ATP or phosphocreatine [35].
Normally the processes of growth and metabolism in the mammalian foetus are supported by a constant uptake of oxygen, glucose, lactate, and amino acids across the umbilical circulation [36]. If the availability of these substrates to the foetus is limited, foetal growth decreases. It is widely assumed that, once the chorioplacenta is functional amino acid nutrition occurs by the direct placental transfers of free amino acids from the maternal to the foetal blood stream [37].

Intestinal sugar and amino acid transports are regulated independently. Inhibition of glucose absorption by high concentrations of certain amino acids has also been noted in mammalian cells in culture and in vitro [38,39]. Intestinal amino acid transport is regulated in a complex way, such as the amino acid transporters are regulated semi-independently of each other, depending of the uptake of amino acids which move via different transporters respond differently to the same dietary amino acid [40] or to dietary levels of protein or protein hydrolysates $[38,39]$. These factors may have contributed to the genesis of the pattern observed for the intestine in the present study.

Although we observed differences in amino acid uptake related to leucine excess diet, we observed no such differences in D-glucose uptake, except in the pregnant groups. The effects of tumor growth in reducing glucose and methionine absorption rate were evident. On the other hand, leucine absorption was increased in the tumor bearing groups. Conversely, exchanging one dietary sugar for another has specific effects on sugar uptake but not on amino acid uptake [38]. Simultaneous reciprocal changes in dietary protein and carbohydrate levels affect sugar uptake and amino acid uptake in opposite directions. Thus intestinal sugar uptake appears to be regulated by dietary sugars or carbohydrates, amino acid uptake by dietary amino acids or proteins.

A priori, dietary supplementation by different amino acids might have led to different rates of amino acid transport through some non-specific mechanism, such as differences in intestinal mucosal mass or architecture or energy supply or $\mathrm{Na}+$ gradient [38]. Although previous studies have showed that there was a reduction on the ratio gut mass/ protein content in groups which were submitted to tumor implant or food restriction decreasing nutrient intestinal absorption [14], in the present study, this ratio can not be related to leucine absorption in pregnant tumor bearing rats. The decrease in glucose intestinal absorption was due to reduction in the food intake; as glucose absorption is up-regulated and depends on its carrier and the pregnant groups ( $\mathrm{P}$ and $\mathrm{L}$ ) were adapted to a nonspecific regulation of carriers which can be accompanied by mucosal hyperplasia. The W and WL group showed de- 
crease in glucose and methionine absorption compared to respective groups ( $\mathrm{P}$ and $\mathrm{L}$ ). However, analysing leucine absorption these tumor bearing groups showed changes in methionine absorption which can not be related to reduction in rat mass/ protein gut, but probably to other effects. These facts might explain why methionine absorption was significantly increased in leucine supplemented diet group (L, WL and Lp, Figure 2). In addition, Hirst [41] reviewed the amino acid absorptive mechanisms and reported that during nutritional manipulations there are carrier adaptations, which could have accounted for the differences found in the tumor -bearing groups of the present study. Thus the amino acid transport alterations related to diet supplementation with different amino acids might involve specific effects on transporters, especially when associated with neoplastic growth. The mechanisms involved in the physiological impact of leucine on the effects of tumor growth remains to be further elucidated.

Although, leucine did not appear to protect fetal growth impairment when a tumor is present, the major effect of leucine supplementation during pregnancy in tumorbearing rats was to prevent experimental hypoglycaemia and promote high leucine absorption, maybe increasing the availability of the amino acid for neoplasic cells and host utilization. This may have contributed to the better preservation of body weight gain, food intake and muscle protein observed in the supplemented rats in relation to the non supplemented ones.

\section{Competing Interests}

None Declared

\section{Acknowledgements}

We thank Dr. Juvenal Marcondes Neto for computing support. We are also grateful to Ajinomoto Interamericana Ind. \& Com. Ltda, for providing LLeucine, to Corn Products Brasil Ingredientes fro providing cornstarch and Roche Industrial \& Quimica S.A. for providing the vitamin mix. Financial support: Fapesp (01/02I35-3, 98/I6022-I, 96/9463-6).

Author I G.V. carried out the experiments and biochemical assays

Author 2 M.A.R.M. participated in the design of the study

Author 3 M.C.C.G.M. conceived of the study and participated in its design and coordination.

\section{References}

I. Inui A: Cancer anorexia-caquexia syndrome. Are neuropeptides the key? Cancer Res I999, 59( I5):4493-450 I

2. Tisdale MJ: Metabolic abnormalities in cachexia and anorexia. Nutrition 2000, I 6(10): 1013-4

3. Bruera $\mathrm{E}: \mathrm{ABC}$ of palliative core, anorexia, cachexia and nutrition. BM] 1997, 3 I 5: 1219-22

4. Lazo AP: Amino acids and glucose utilization by different metabolic pathways in ascites-tumor cells. Eur J Biochem 1981, | | 7:19-25

5. Smith HL, Tisdale MJ: Mechamism of muscle protein degradation in cancer cachexia. Br J Cancer 1993, 68:314-318

6. Adibi AS: Metabolism of branched-chain amino acids in altered nutrition. Metabolism 1976, 25:12587-1302
7. Block RJ, Weiss KW: Amino acids Handbook. Methods and results of protein analysis. Springfiels, IL: Thomas 1956, 34I-346

8. Nair KS, Schwartz RG, Welle S: Leucine as a regulator of whole body and skeletal muscle protein metabolism in humans. Am J Physiol 1992, 263(5 Pt I):E928-34

9. Argiles JM, Lopes-Soriano FJ: The oxidation of leucine in tumour-bearing rats. Biochem J 1990, 268:24I-244

10. Goodlad RA, Al-Mukhtar MY, Ghatei MA, Bloom SR, Wright NA: Cell proliferation, plasma enteroglucagon and plasma gastrin levels in starved and refed rats. Virchows Arch B Cell Pathol Ind Mol Pathol 1983, 43(I):55-62

I I. Costelli P, Llovera M, Garcia-Martinez C, Carbo N, Lopez-Soriano FJ Argiles JM: Enhanced leucine oxidation in rats bearing an ascites hepatoma (Yoshida $\mathrm{AH}-130$ ) and itsreversal by clenbuterol. Cancer Lett 1995, 9 I(I):73-78

12. loachim HL, Moroson $\mathrm{H}$ : Protective effect of pregnancy against transplantation of lymphoma in rats. J Nat Cancer Inst 1986, 77:809-14

13. Gomes-Marcondes MCC, Cury L, Curi R: Consequences of Walker 256 tumor growth for the placental/fetal development in rats. Cancer Res Ther and Con 1998, 5:277-83

14. Gomes-Marcondes MCC, Honma HN, Areas MA, Cury L: Effect of Walker 256 tumor growth on intestinal absorption of leucine, methionine and glucose in newly weaned and mature rats. Braz J Med Biol Res 1998, 3 I : I 345- I 348

15. Ventrucci G, Mello MAR, Gomes-Marcondes MCC: Effect of a leucine-supplemented diet on body composition changes in pregnant rats bearing Walker 256 tumor. Braz J Med Biol Res 2001, 34:333-38

16. Vinardell MP: Ages influences on amino acid intestinal transport. Comp Biochem Physiol 1992, I 03:169-I7I

17. Baker HL: Reproduction and breeding. The laboratory rat. (Edited by: HL Baker, JR Lindseyl, SH Weisbroth) New York, Academic Press I99I, I53-I68

18. Reeves PG, Nielsen FH, Fahey J: AIN-93 purified diets for laboratory rodents: final report of the American Institute of Nutrition ad hoc writing committee on the reformulation of the AIN-76 rodent diet. J Nutr 1993, I23: 1939-5 I

19. Trinder P: Determination of blood glucose using on oxidaseperoxidase system with a non carcinogenic chromogen. J Clin Path 1969, 22:|58-61

20. Mccarthy TE, Sulivan MX: A new and highly specific colorimetric test of methionine. J Biol Chem 1941, I 41:87|-876

21. Rosen $\mathrm{H}$ : A modified ninhydrin colorimetric analysis of amino acids. Arch Biochem Biophys 1957, 67: I-I5

22. Bradford $M M: A$ rapid and sensitive method for quantification of microgram quantities of protein utilizing the principle of protein-dye-binding. Anal Biochem 1976, 72:248-254

23. Gad SC, Weil CS: Statistic for toxicologists. Principles and Methods of toxicology. (Edited by: H Wallace) Raven Press Ltd., New York 1994, $221-274$

24. Guaitani A, Torre PD, Morasca L, Pintus C, Bartosek I: Two lines of Walker carcinoma 256: Their peculiarities and different interaction with the host. Tumor 1983, 69:1-9

25. Hartl WH, Demmelmair H, Janch KW, Bkoletzko, Schildberg FW: Effect of glucagon on protein synthesis in human rectal cancer in situ. Ann Surg 1998, 227:390-7

26. Mcnurlan MA, Fern EB, Garlick PJ: Failure of leucine to stimulate protein synthesis in vivo. Biochem $J$ 1982, 204:831-838

27. $\mathrm{Li}$ JB, Jefferson LS: Influence of amino acid availability on protein turnover in perfused skeletal muscle. Biochim Biophys Acta 1978, 544(2):351-9

28. Fulks RM, Li JB, Goldberg AL: Effects of insulin, glucose, and amino acids on protein turnover in rat diaphragm. J Biolog Chemistry 1975,250 (I):290-8

29. Mitch WE, Walser M, Sapir DG: Nitrogen sparing induced by leucine compared with that induced by its keto analogue, alpha-ketoisocaproate, in fasting obese man. J Clin Invest 1981, 67(2):553-62

30. Sapir DG, Stewart PM, Walser M, Moreadith C, Moyer ED, Imbembo $A L$, Rosenshein NB, Munoz S: Effects of alpha-ketoisocaproate and of leucine on nitrogen metabolism in postoperative patients. Lancet 1983, I(8332): 1010-4

31. Hunter DC, Weintraub M, Blackburn GL, Bistrian BR: Branched chain animo acids as the protein component of parenteral nutrition in cancer cachexia. Br J Surg 1989, 76: | 149-153 
32. Miwa Y, Kato M, Moriwaki H, Okuno M, Sigihara J, Ohnishi H: Effects of branched-chain amino acids infusion on protein metabolism in rats with acute hepatic failure. Hepatology 1995, 22:291296

33. Schaur RJ, Semmelro HJ, Schreibm W, Tillian HM, Schauens E: Tumor host interactions. 5. Nitrogen metabolism in Yoshida sarcoma-bearing rats. Reduction of growth rate and increase in survival time by administration of physiological doses of branched-chain amino acids. J Can Res Clin Oncol 1980, 97:285293

34. Garlick PJ, Grant I: Amino acids infusion increases the sensitivity of muscle protein synthesis in vivo to insulin. Biochem J 1988, 254:579-584

35. Busquets S, Alvarez B, Llovera M, Agell N, Lopes-Soriano FJ, Argiles JM: Branched-chain amino acids inhibit proteolysis in rat skeletal muscle: mechanisms involved. J Cell Physiol 2000, 184(3):380-4

36. Milley JR: Ovine fetal leucine kinetics and protein metabolism during decreased oxygen availability. Am J Physiol 1998, 274(4 Pt I):E6I8-26

37. Beckman DA, Mullin JP, Brent RL, Lloyd JB: Leucine transport from mother to fetus in rat: role of the visceral yolk sac. $\mathrm{Nu}$ trition Res 1998, I 8(10): 1783-89

38. Stein TP, Hoyt RW, Settle RG, O'Toole M, Hiller WD: Determination of energy expenditure during heavy exercise, normal daily activity, and sleep using the doubly-labelled-water $(2 \mathrm{H} 2$ 1 8) method. Am J Clin Nutr 1987, 45(3):534-539

39. Buddington RK, Chen JW, Diamond JM: Dietary regulation of intestinal brush-border sugar and amino acid transport in carnivores. Am J Physiol I99I, 26 I:R793-R80 I

40. Uhing $M R$, Arango $V$ : Intestinal absorption of proline and leucine in chronically catheterized rats. Gastroenterology 1997, I 13:865-874

4I. Hirst BH: Dietary regulation of intestinal nutrient carriers. Proc Nutrition Soc 1993, 52:315-324

\section{Pre-publication history}

The pre-publication history for this paper can be accessed here:

http://www.biomedcentral.com/1471-2407/2/7/prepub

Publish with BioMed Central and every scientist can read your work free of charge

"BioMedcentral will be the most significant development for disseminating the results of biomedical research in our lifetime."

Paul Nurse, Director-General, Imperial Cancer Research Fund

Publish with BMC and your research papers will be:

- available free of charge to the entire biomedical community

- peer reviewed and published immediately upon acceptance

- cited in PubMed and archived on PubMed Central

- yours - you keep the copyright

Submit your manuscript here:

BioMedcentral.com 